\title{
Multivariate Analysis of the Offensive Phase in High-Performance Women's Soccer: A Mixed Methods Study
}

\author{
Iyán Iván-Baragaño ${ }^{1, * \mathbb{C}}$, Rubén Maneiro ${ }^{2, * \mathbb{D}}$, José L. Losada ${ }^{3}$ and Antonio Ardá ${ }^{1}$ \\ 1 Department of Physical and Sport Education, University of A Coruña, 15179 A Coruña, Spain; ardasd@udc.es \\ 2 Department of Science of Physical Activity and Sport, Pontifical University of Salamanca, \\ 37002 Salamanca, Spain \\ 3 Department of Social Psychology and Quantitative Psychology, University of Barcelona, \\ 08035 Barcelona, Spain; antonio.arda@udc.es \\ * Correspondence: iyan.ivan@udc.es (I.I.-B.); rubenmaneirodios@gmail.com (R.M.)
}

Citation: Iván-Baragaño, I.; Maneiro, R.; Losada, J.L.; Ardá, A. Multivariate Analysis of the Offensive Phase in High-Performance Women's Soccer: A Mixed Methods Study.

Sustainability 2021, 13, 6379.

https://doi.org/10.3390/su13116379

Academic Editors: Antonio

Hernández-Mendo, Coral Falco,

Verónica Morales-Sánchez,

Cristina Menescardi and

Tomas Herrera-Valenzuela

Received: 1 May 2021

Accepted: 1 June 2021

Published: 4 June 2021

Publisher's Note: MDPI stays neutral with regard to jurisdictional claims in published maps and institutional affiliations.

Copyright: (c) 2021 by the authors. Licensee MDPI, Basel, Switzerland. This article is an open access article distributed under the terms and conditions of the Creative Commons Attribution (CC BY) license (https:// creativecommons.org/licenses/by/ $4.0 /)$.

\begin{abstract}
Currently, there are still few studies on the tactical and contextual criteria that determine offensive success in women's soccer. The objectives of this study were to discover contextual and tactical criteria that show an association with success in elite women's soccer and to establish a multivariate predictive model for the offensive phase. For this, 2323 ball possessions were analyzed in FIFA Women's World Cup 2019 via direct observation. In addition, eight semi-structured interviews were conducted with women's soccer coaches and players. For direct observation, a bivariate analysis between the analysed criteria and possession's outcome was suggested. Additionally, a multivariate predictive analysis was proposed via a decision tree method. To analyze the interviews, a sequential analysis of delays and polar coordinates analysis were carried out. It was established a multi-variant model of offensive success based on possession zone (middle offensive), initial offensive intention (progress) and start zone (preoffensive or offensive) criteria. The probability of offensive success was $75.2 \%$ interactively between those criteria. In addition, the analysis of the interviews allowed us to conclude that criteria related to technical-tactical performance, decision-making and physical capacities of the players will be decisive in increasing the probabilities of success.
\end{abstract}

Keywords: technical-tactical performance; women's soccer; opposition sports; observation; mixed methods; ball possession

\section{Introduction}

Soccer is the most played sport in the world. For this reason, it is also the sport that has awakened the most interest in the field of research [1]. Its popularity has meant that, over the last few decades, studies of different aspects of the game have created a theoretical and scientific framework of great value for professionals in this sport. On the other hand, it is only since the beginning of this century that scientific publications about women's soccer have begun to increase [2]. This lack of publication has conditioned the sporting development of this modality, forcing trainers and researchers to resort to using the results taken from the male equivalent, despite the differences in the development of the game between the two sexes [2,3].

In the last few years, several authors have developed scientific knowledge about soccer played by women and the variables of the game that shape performance in this sport [3]. Research is mainly related to the parameters concerning the physiology of female soccer players [2], although these elements do not represent an approach to the tactical reality of the game. Aspects related to time-motion during matches were studied by Hewitt, Norton and Lyons [4], observing a decrease of approximately $5 \%$ in the total distance covered by the players in the second halves. Bradley et al. [5] came to the same conclusion, along with the observation that this represented a significant difference from men's elite soccer. Other research has focussed on the study of technical variables with the aim of establishing 
differences between the two sexes [5,6], together with associating the appearance of these technical elements of the game with success. Along the same lines as De Jong et al. [3], a recent ambitious study found that the most important element in achieving success is scoring the first goal. These authors also observed that success is highly linked to indicators of aggressive and physical play such as duels and aerial duels won [3] between women soccer players. Kubayi and Larkin [7] analysed the FIFA Women's World Cup France 2019 and observed that the winning teams had more ball possession time and made more passes, which resulted in more goal opportunities.

For some time, most of the studies on performance indicators in soccer were carried out from a quantitative perspective. More recently, some authors have tried to find out the criteria that determine success in soccer based on qualitative methodology. Due to the high complexity in soccer analysis, in recent years different studies have been published using the integration of both methodologies as a basis, under the paradigm of Mixed Methods [8-10].

Despite the growth in interest over the last few years, bibliography in relation to achieving offensive success in women's soccer remains scarce. In this sense, the main success indicator in soccer is the goal $[11,12]$ and, due to the little casuistry during the development of a soccer match, it means that achieving this and creating goal opportunities has fundamental value for technicians and players [13].

In men's soccer, the association between contextual and tactical criteria and success during the development of the game in the offensive phase has been studied over numerous decades up to the present day. The contextual match status variable $[12,14,15]$ proved to be an important factor that modified aspects such as the possession zone. James, Mellalieu and Holley [16] observed that teams moved the possession zone to more defensive areas when they were winning, with the subsequent negative link to offensive success, as shown by Casal et al. [17] later. In women's soccer, it was also seen that this was a variable that modified ball possession following analysis of the FIFA Women's World Cup Canada 2015 [18]. The kind of start of possession and the zone in which it was produced proved to be tactical indicators significantly linked to success in men's soccer $[19,20]$ and in women's soccer [21]. It was also shown that once possession of the ball was recovered, the offensive tactical intention [22] significantly modified the development of offensive actions in men's soccer: the teams that showed a tactical intention to move quickly towards the rival goal had a greater probability of finishing their offensive actions successfully. On the other hand, the spatial context of interaction $[23,24]$ proved to be a variable that explained the achieving of high-value offensive situations when contexts were produced in which the team initiating the offensive action did so with only the rival backfield between the ball and the rival goal [24].

Other studies have attempted to quantify different variables related to the development of offensive actions such as the time spent in offensive and defensive phase [25-27] observing that the best teams were able to recover possession of the ball more quickly than their opponents [27] independently of the match status. It was also shown that successful offensive actions in soccer do not last long and involve a low number of passes [28]. On the other hand, in terms of the dynamic of the game itself, there has been an attempt to discover the influence of the rival team's tactical defensive behaviour in achieving offensive success, by analysing variables such as the defensive positioning of the opponent at the beginning of the offensive action $[28,29]$, the defensive intention $[25,30]$ and the rival defensive organisation [22].

Despite the existing evidence concerning the behaviour of the tactical and contextual criteria and success in men's soccer, women's soccer is currently devoid of a high number of references that would allow clear conclusions to be reached about this aspect [31]. In spite of the increase over the last few years in publications that have allowed conclusions to be made regarding technical [3,5-7] or tactical parameters [18,21,32], a more in-depth analysis is needed of this soccer that has awakened so much interest in the last decade [33]. 
Mixed Methods are currently presented as one of the most appropriate methodologies to knowing the criteria that are associated with success in women's soccer [9]. This methodology was applied in this study in search of integration between qualitative and quantitative perspectives [10], in the third paradigm of research [34] in a complementary way to achieve the goals of this study. The integration of qualitative and quantitative data from the mixed methods methodology allowed us to achieve the objective of this study in a comprehensive way. Quantification of the data by itself is not enough to explain the complex behavior in high-level soccer. Likewise, sole qualitative analysis can lead to subjectivity. For these reasons, the application of mixed methods, with a robust quality of the data supported by the experience of the observers [35], makes it possible to approach the problem of soccer from a comprehensive perspective. Therefore, its use in the analysis of soccer performance should be developed in the coming years.

For all this, the aims of this study are twofold: on the one hand, (i) to discover the contextual and tactical criteria that show an association with success in elite women's soccer, and on the other hand, (ii) to establish a multivariate predictive model for the offensive phase from tactical and contextual criteria. If these goals were met, coaches and players will obtain relevant information on how to develop ball possessions in elite women's soccer.

\section{Materials and Methods}

\subsection{Design}

A Mixed-Method design was applied for this study from direct observation and indirect observation [35]. From direct observation, ball possessions in the FIFA Women's World Cup France 2019 were analyzed. From indirect observation, eight semi-structured interviews with female soccer coaches and players were analyzed.

Observational methodology was used in this study due to its suitability for observation and analysis of sports performance developed in a natural and spontaneous context [36].

It has a nomothetic observational design—various study units analysed; punctualdifferent sessions analysed over time; and multidimensional-plurality and concurrence of various response levels are reflected in the observation instrument. In terms of this classification, this work is framed within quadrant III of those proposed by Anguera et al. [37].

\subsection{Participants and Sample}

Direct observation. The study units were ball possessions in the FIFA Women's World Cup France 2019 [38,39]. A total of 2323 were analysed from the 16 matches of the final phase of the tournament. Both teams were analysed in each match. The fact that the analysed matches were from the knockout stage-in which a win is needed to progress in the tournament-eliminates any result speculation on the part of the observed teams. Additionally, all allowed matches were close games. In the matches analyzed, there were no major differences between teams. This fact did occur in group stage matches (e.g., EE.UU. 13-0 Thailand). With a view to obtaining the utmost rigour in the results, any actions taking place during extra time were excluded from the recording and analysis. The inclusion criteria used for the recording of offensive actions was adapted from Garganta [40]. Actions in which the attacking team fulfilled any of the following requirements were coded: (i) three consecutive contacts with the ball or (ii) a finished pass - as long as it lasted more than three seconds, or (iii) a shot taken. The offensive actions lasted from the first contact with the ball up to (i) possession changing to the rival team or (ii) there being a regulatory interruption in the game.

Indirect observation. A total of eight semi-structured interviews [8,9] with players and coaches were analyzed (Table 1). The coaches and players were selected by the authors of the study. All the coaches were UEFA PRO coaches and had experience as head coach in the Spanish women's first division. In the case of the players, at the time of the interviews, all of them were part of one of the teams in the Spanish women's first division. Those interviewed included the second coach of the Spanish National team, a player participating 
in the FIFA Women's World Cup Canada 2015 and a player participating in the FIFA Women's World Cup France 2019. The semi-structured interviews were prepared by a group of three experts in the field, two of them Ph.D. in Sports Sciences and a predoctoral researcher in Sport Sciences. A first pilot interview with five players was conducted. This interview served as the basis for the elaboration of the final interview, after discussion among the group of experts. The definitive interview consisted of 15 questions. According to Anguera [41], it was a semi-structured, one to one and non-directed interview. All of them were requested and carried out by the study authors. The interviews lasted between 36 and $75 \mathrm{~min}$. The transcription of interviews was carried out ad verbatim and the segmentation was carried out based on the orthographic and syntactic criteria [42]. In total, 2410 text units were analyzed.

Table 1. Characteristics of the interviewees.

\begin{tabular}{ccccc}
\hline Int. & Sex & Role & Team & Age [Years] \\
\hline 1 & M & C & Real Sociedad & $50[27]$ \\
2 & F & P & Spanish Women's National Team & $22[7]$ \\
3 & F & P & Spanish Women's National Team & $25[7]$ \\
4 & M & C & R.C. Deportivo de la Coruña & $38[9]$ \\
5 & M & C & U.D. Levante & $41[12]$ \\
6 & M & C & Madrid C.F.F. & $28[8]$ \\
7 & F & C & Spanish Women's National Team & $39[21]$ \\
8 & F & P & Spanish Women's National Team & $33[13]$ \\
\hline
\end{tabular}

Note. $\mathrm{M}$ = Male; $\mathrm{F}=$ Female; $\mathrm{C}=$ Coach; $\mathrm{P}$ = Player; Int = Interview; Years = Years of experience as player and/or coach.

\subsection{Observation Instruments}

The direct observation instrument (Table 2) used in this study to analyse ball possessions in FIFA Women's World Cup was created ad hoc and was a combination of field formats and category systems [37] which gives it the necessary rigour and flexibility for studying the analysed actions.

The observation instrument used by Maneiro et al. [18] was taken as a reference and various criteria were added with the aim of testing out others that proved to be significant in previous literature. The categories and definitions of the sub-criteria Start Zone (length) and Interaction Context were taken from Castellano [23] and Castellano and Hernández Mendo [24]. The Start Zone (width) was coded by dividing the field of play into two lateral corridors and one central; the lateral corridors went from the touchline up to the projections of the lateral line of the penalty area. The sub-criteria Defensive Organization can be consulted in the publication by Casal et al. [43] Finally, the sub-criteria Defensive Positioning and Defensive Intention were taken from the instrument "REOFUT" [28]. In both sub-criteria, the definitions of the categories were adapted and classification of the actions allowed according to the collectivity and social interaction of the players in the analysed actions [44]. For the Possession outcome criteria, the following categories were defined: (i) Goal: ball possession ended in a goal for the observed team; (ii) Shot: ball possession ended with a shot for the observed team; (iii) Sent to Area: ball possession ended with a pass or a cross to the penalty area with the intention that the ball was shot by a player from the observed team; and (iv) No Success: ball possession was unsuccessful.

The indirect observation instrument used in this study was created ad hoc and was a combination of field formats and category systems. An indirect observation instrument was structured combining the ascending and descending path from the transcription of the interviews. According to Izquierdo and Anguera [45] in this type of observation, one of the main issues is in the construction of the indirect observation instrument, which can be built ad hoc according to the research problem. The instrument consisted of two dimensions and 28 criteria, which were displayed at a first and second level creating the entire instrument. 
Table 2. Direct observation instrument. Field format and category systems.

\begin{tabular}{|c|c|c|}
\hline Dimensions & Criteria & Categories \\
\hline \multirow{4}{*}{$\begin{array}{l}\text { Dimension 1. Identification } \\
\text { of action }\end{array}$} & Observed Team & \\
\hline & \multirow{3}{*}{ Match Outcome } & Win \\
\hline & & Lose \\
\hline & & Draw \\
\hline \multirow{32}{*}{$\begin{array}{l}\text { Dimension 2. Start of } \\
\text { possession }\end{array}$} & \multirow{7}{*}{ Time } & $1 Q$ \\
\hline & & $2 \hat{Q}$ \\
\hline & & $3 Q$ \\
\hline & & $4 \hat{Q}$ \\
\hline & & $5 \mathrm{Q}$ \\
\hline & & $6 \hat{Q}$ \\
\hline & & Winning \\
\hline & \multirow[t]{2}{*}{ Match Status } & Drawing \\
\hline & & Losing \\
\hline & \multirow{3}{*}{ Start Form } & Set Play \\
\hline & & Transition \\
\hline & & Defensive \\
\hline & \multirow{4}{*}{ Start Zone (length) } & Predefensive \\
\hline & & Middle \\
\hline & & Preoffensive \\
\hline & & Offensive \\
\hline & \multirow[b]{2}{*}{ Start Zone (width) } & Left \\
\hline & & Central \\
\hline & \multirow{2}{*}{ Defensive Organization } & $\begin{array}{c}\text { Kignt } \\
\text { Organized }\end{array}$ \\
\hline & & Circumstantial \\
\hline & \multirow[t]{3}{*}{ Defensive Positioning } & Medium \\
\hline & & Advanced \\
\hline & & MM \\
\hline & \multirow{9}{*}{ Interaction Context } & A0 \\
\hline & & AA \\
\hline & & $\mathrm{AM}$ \\
\hline & & $\mathrm{AR}$ \\
\hline & & MA \\
\hline & & MR \\
\hline & & RA \\
\hline & & $\mathrm{RM}$ \\
\hline & & PA \\
\hline \multirow{8}{*}{$\begin{array}{c}\text { Dimension 3. Possession } \\
\text { development }\end{array}$} & Offensive Intention & $\begin{array}{c}\text { Keep } \\
\text { Progress }\end{array}$ \\
\hline & Defensive Intention & No pressure \\
\hline & \multirow{4}{*}{$\begin{array}{c}\text { MD (seconds) } \\
\text { MO (seconds) } \\
\text { Possession Time } \\
\text { Passes }\end{array}$} & \\
\hline & & \\
\hline & & \\
\hline & & \\
\hline & \multirow{2}{*}{ Possession Zone } & MD \\
\hline & & $\mathrm{MO}$ \\
\hline $\begin{array}{c}\text { Dimension } 4 \text {. Possession } \\
\text { outcome }\end{array}$ & Possession Outcome & $\begin{array}{c}\text { Goal } \\
\text { Shot } \\
\text { Sent to Area } \\
\text { No Success }\end{array}$ \\
\hline
\end{tabular}

\subsection{Recording Instrument}

For direct observation, the matches were recorded from public television and analysed post-event. As they are public images it was not necessary to obtain the personal authorisation of the players who took part in the analysed matches. 
For indirect observation, the interviews conducted were recorded by the interviewer and transcribed ad verbatim. All participants received informed consent before conducting the interviews.

Furthermore, this study was approved by the Research and Teaching Ethics Committee of the Universidade da Coruña (approval number: CEID-UDC-2019-0024)

The recording instrument used, both for the direct and indirect observation was LINCE PLUS v 1.1.1 [46]. This tool allows the visualisation, analysis and recording of actions via a single screen, by various observers simultaneously.

\subsection{Procedure}

Three observers (soccer trainers, two of them with PhDs and considerable observational methodology experience) were trained in and familiarised with the observation instruments over four sessions [47].

For direct observation, quality control of the data was carried via the calculation of Cohen's [48] inter-observer kappa coefficient for each of the criteria of the observation instrument. This calculation produced an average value of 0.869 which shows excellent quality according to the Landis and Koch scale [49].

For indirect observation, a qualitative data quality control was carried out via consensual agreement and quantitative data quality control via the calculation of Cohen's intra-observer kappa coefficient. This calculation produced an average value of 0.708 . This value was considered substantial [49] for this study as it was an indirect observation.

\subsection{Data Analysis}

\subsubsection{Ball Possessions Analysis}

Bivariate analysis was suggested between the analysed criteria and the dichotomous possession outcome criteria, through the Chi-squared statistic and Fisher's exact test when necessary. For this analysis, the possession outcome criteria were transformed into dichotomous ( $0=$ No Success; 1 = Success). The Goal, Shot and Sent to Area categories were considered Success. All other actions were considered as No Success. Normality of the continuous type criteria was checked via the Shapiro-Wilk Test $(p<0.05)$ and was rejected. The U Mann-Whitney Test was used to check whether there were differences between both groups for this type of criteria.

Finally, a multivariate predictive analysis was carried out via a decision tree. This technique, which is rarely applied in the field of physical activity in sport, has proved to possess good applicability and results interpretation in this field. For this reason, over the last few years, different studies have been developed via this type of analysis in soccer [18,32,49-51], five-a-side soccer [52] and Australian soccer [53].

The dependent variable input into the decision tree was that of possession outcome in its dichotomous recoding. All the criteria included in the observational instrument formed part of the model as predictive. The tree growth method was Chi-Squared Automatic Interaction Detection (CHAID). This model chooses, in each decision node, the independent or predictive variable that shows the strongest association with the variable being predicted, joining together the different categories of each one when there are no significant differences. Taking into account the total sample size and to avoid pruning the tree, it was decided to establish a minimum of 100 cases for each node. The established significance level was $p<0.05$ for the inclusion of new nodes on the tree. Lastly, the tree decision model was validated via the sample division method ( $50 \%$ of the total training sample, $50 \%$ of the total validation sample). The tree decision model correctly classified $79 \%$ of cases and the risk estimation of the model was 0.210 .

The statistical analysis was performed using SPSS 25.0 (IBM Corp. Released 2017. IBM SPSS Statistics for Windows, Version 25, IBM Corp., Armonk, NY, USA). 


\subsubsection{Interview's Analysis}

"Quantitizing" of text units was carried out from the narrative transcription of interviews to a matrix of codes [44]. Two types of analysis were carried out: sequential analysis of delays and analysis of polar coordinates using HOISAN free program [54]. Those categories and behaviors that presented results higher than $\mathrm{Z}>1.96$ were considered statistically significant $(p<0.05)$ for both the sequential analysis of delays and the polar coordinate analysis.

\section{Results}

\subsection{Direct Observation}

A total of 2323 offensive actions were recorded in 16 analysed matches. These data gave an average value of 145.2 offensive actions per match. An initial descriptive analysis of the Possession Outcome criteria leads to the observation that, of the total number of possessions, $(\mathrm{n}=1744 ; 75.1 \%)$ ended in No Success. In terms of success: $14.8 \%$ of the actions ended with Sent to Area, 9.0\% ended in Shot and just 1.1\% ended with Goal. We consider that one in every four actions $(n=579 ; 24.9 \%)$ ended in relative success for the attacking team (Goal, Shot, Sent to Area) while the rest of the actions ended with No Success.

On a bivariate level, twelve of the sixteen observational instrument criteria show significant differences based on the result of the action (Table 3). The criteria that showed significant differences in the chi-squared test were Time $(p<0.001)$, Start Form $(p<0.05)$, Start Zone (length) $(p<0.001)$, Defensive Organization $(p<0.001)$, Defensive Positioning $(p<0.001)$, Interaction Context $(p<0.001)$, Offensive Intention $(p<0.001)$, Defensive Intention $(p<0.001)$ and Possession Zone $(p<0.001)$. In terms of continuous type criteria, the significant differences via the Mann-Whitney test appeared in the following criteria: Possession Time in Own Half (MD) $(p<0.001)$, Possession Time in Opponent's Half (MO) $(p<0.001)$ and Passes $(p<0.005)$.

On a multivariate level, a twelve-node decision tree was produced (Figure 1), seven of which are terminal. The model shows a total correct classification percentage of $79 \%$. A descending reading of the results was carried out, in accordance with the structure of the tree.

The first node 0 is based on Possession Outcome with 1.159 observations and a majority of No Success ( $n=861,74.3 \%)$ against Success $(n=298,25.7 \%)$. The first criteria taken into consideration by the algorithm was Possession Zone $\left(\chi^{2}=215.447 ; p<0.001\right)$, branching off into two, and nodes corresponding to the categories MD and MO. In this branching off, we can observe that the possibilities of success increase in the MO category, against the MD. In Node 1 (MD) we can see a total of 578 observations (95.3\% No Success; $4.7 \%$ Success). In Node 2 (MO) there is a notable increase in the percentage of success ( $\mathrm{n}=581 ; 53.4 \%$ No Success; $46.6 \%$ Success). Nodes 3, 4 and 5 of the decision tree are terminal and were input as the following predictive variable (from the MD onwards), the Possession Time in Opponent's Half $(\mathrm{MO})\left(\chi^{2}=125.810 ; p<0.001\right)$. We can observe in these three nodes how the probability of success increases as the value of the Possession Time in Opponent's Half increases. We can see a $0.5 \%$ probability of success out of a total of 429 observations in Node 3 when possession time in the opponent's half is less than or equal to four seconds. Node 4 shows 84 observations, and we see that the probability of success rises to $14.3 \%$ when possession time in the opponent's half is 5,6 or $7 \mathrm{~s}$. However, when that time is over seven seconds the possibility of success rises to $20 \%$ (Node 5,65 observations). 
Table 3. Bivariate analysis based on possession outcome.

\begin{tabular}{|c|c|c|c|c|}
\hline Criteria & Categories & No Success $n=1744$ & Success $n=579$ & $p$ Overall \\
\hline \multirow{3}{*}{ Match Outcome } & Win & $665(38.1 \%)$ & $238(41.1 \%)$ & \multirow{3}{*}{0.207} \\
\hline & Lose & $754(43.2 \%)$ & $226(39.0 \%)$ & \\
\hline & Draw & $325(18.6 \%)$ & $115(19.9 \%)$ & \\
\hline \multirow{6}{*}{ Time } & $1 Q$ & $321(18.4 \%)$ & $89(15.4 \%)$ & \multirow{6}{*}{$<0.001$} \\
\hline & $2 \hat{Q}$ & $314(18.0 \%)$ & $79(13.6 \%)$ & \\
\hline & $3 Q$ & $311(17.8 \%)$ & $92(15.9 \%)$ & \\
\hline & $4 \mathrm{Q}$ & $277(15.9 \%)$ & $90(15.5 \%)$ & \\
\hline & $5 \mathrm{Q}$ & $263(15.1 \%)$ & $102(17.6 \%)$ & \\
\hline & $6 \hat{Q}$ & $258(14.8 \%)$ & $127(21.9 \%)$ & \\
\hline \multirow{3}{*}{ Match Status } & Winning & $409(23.5 \%)$ & $131(22.6 \%)$ & \multirow{3}{*}{0.519} \\
\hline & Drawing & $742(42.5 \%)$ & $236(40.8 \%)$ & \\
\hline & Losing & $593(34.0 \%)$ & $212(36.6 \%$ & \\
\hline \multirow{2}{*}{ Start Form } & Set Play & $573(32.9 \%)$ & $161(27.9 \%)$ & \multirow{2}{*}{0.026} \\
\hline & Transition & $1171(67.1 \%)$ & 417 (72.1\%) & \\
\hline \multirow{5}{*}{ Start Zone (length) } & Defensive & $322(18.5 \%)$ & $44(7.6 \%)$ & \multirow{5}{*}{$<0.001$} \\
\hline & Predefensive & $666(38.2 \%)$ & $105(18.1 \%)$ & \\
\hline & Middle & $464(26.6 \%)$ & $161(27.8 \%)$ & \\
\hline & Preoffensive & $267(15.3 \%)$ & $218(37.7 \%)$ & \\
\hline & Offensive & $25(1.4 \%)$ & $51(8.8 \%)$ & \\
\hline \multirow{3}{*}{ Start Zone (width) } & Left & $385(22.1 \%)$ & $141(24.4 \%)$ & \multirow{3}{*}{0.17} \\
\hline & Central & $946(54.1 \%)$ & $288(49.7 \%)$ & \\
\hline & Right & $413(23.7 \%)$ & $150(25.9 \%)$ & \\
\hline \multirow{2}{*}{$\begin{array}{c}\text { Defensive } \\
\text { Organization }\end{array}$} & Organized & $1711(98.3 \%)$ & $545(94.1 \%)$ & \multirow[b]{2}{*}{$<0.001$} \\
\hline & Circumstantial & $29(1.7 \%)$ & $34(5.9 \%)$ & \\
\hline \multirow{3}{*}{$\begin{array}{l}\text { Defensive } \\
\text { Positioning }\end{array}$} & Low & $674(38.7 \%)$ & $376(65.1 \%)$ & \multirow{3}{*}{$<0.001$} \\
\hline & Medium & $335(10.2 \%)$ & $81(14 \%)$ & \\
\hline & Advanced & $733(42.1 \%)$ & $121(20.9 \%)$ & \\
\hline \multirow{10}{*}{$\begin{array}{c}\text { Interaction } \\
\text { Context }\end{array}$} & MM & $676(38.8 \%)$ & $267(46.1 \%)$ & \multirow{10}{*}{$<0.001$} \\
\hline & $\mathrm{A} 0$ & $0(0 \%)$ & $10(1.7 \%)$ & \\
\hline & AA & $39(2.2 \%)$ & $0(0 \%)$ & \\
\hline & AM & $10(0.6 \%)$ & $5(0.9 \%)$ & \\
\hline & AR & $86(3.7 \%)$ & $107(18.5 \%)$ & \\
\hline & MA & $25(1.4 \%)$ & $4(0.7 \%)$ & \\
\hline & MR & $17(1 \%)$ & $20(3.5 \%)$ & \\
\hline & $\mathrm{RA}$ & $619(35.5 \%)$ & $120(20.7 \%)$ & \\
\hline & $\mathrm{RM}$ & $64(3.7 \%)$ & $14(2.4 \%)$ & \\
\hline & $\mathrm{PA}$ & $206(11.8 \%)$ & $32(5.5 \%)$ & \\
\hline \multirow{2}{*}{$\begin{array}{l}\text { Offensive } \\
\text { Intention }\end{array}$} & Keep & $1133(65.0 \%)$ & $214(37.0 \%)$ & \multirow{2}{*}{$<0.001$} \\
\hline & Progress & $611(35.0 \%)$ & $365(63.0 \%)$ & \\
\hline \multirow{2}{*}{$\begin{array}{l}\text { Defensive } \\
\text { Intention }\end{array}$} & No pressure & $1026(58.9 \%)$ & $422(72.9 \%)$ & \multirow{2}{*}{$<0.001$} \\
\hline & Pressure & $715(41.1 \%)$ & $157(27.1 \%)$ & \\
\hline MD (Seconds) ${ }^{1}$ & & $7.0[3.0-12.0]$ & $0.0[0.0-4.0]$ & $<0.001$ \\
\hline MO (Seconds) ${ }^{1}$ & & $4.0[1.0-8.0]$ & $9.0[6.0-13.0]$ & $<0.001$ \\
\hline Possession Time ${ }^{1}$ & & $12.0[7.0-18.0]$ & $11.0[6.0-19.0]$ & 0.265 \\
\hline Passes $^{1}$ & & $3.0[2.0-5.0]$ & $3.0[2.0-5.00]$ & 0.003 \\
\hline \multirow{2}{*}{ Possession Zone } & MD & $1086(62.4 \%)$ & $57(9.8 \%)$ & \\
\hline & $\mathrm{MO}$ & $655(37.6 \%)$ & $522(90.2 \%)$ & $<0.001$ \\
\hline
\end{tabular}

Note. $\mathrm{n}=$ Frequency; ${ }^{1}$ Values are presented as medians and interquartile range. 


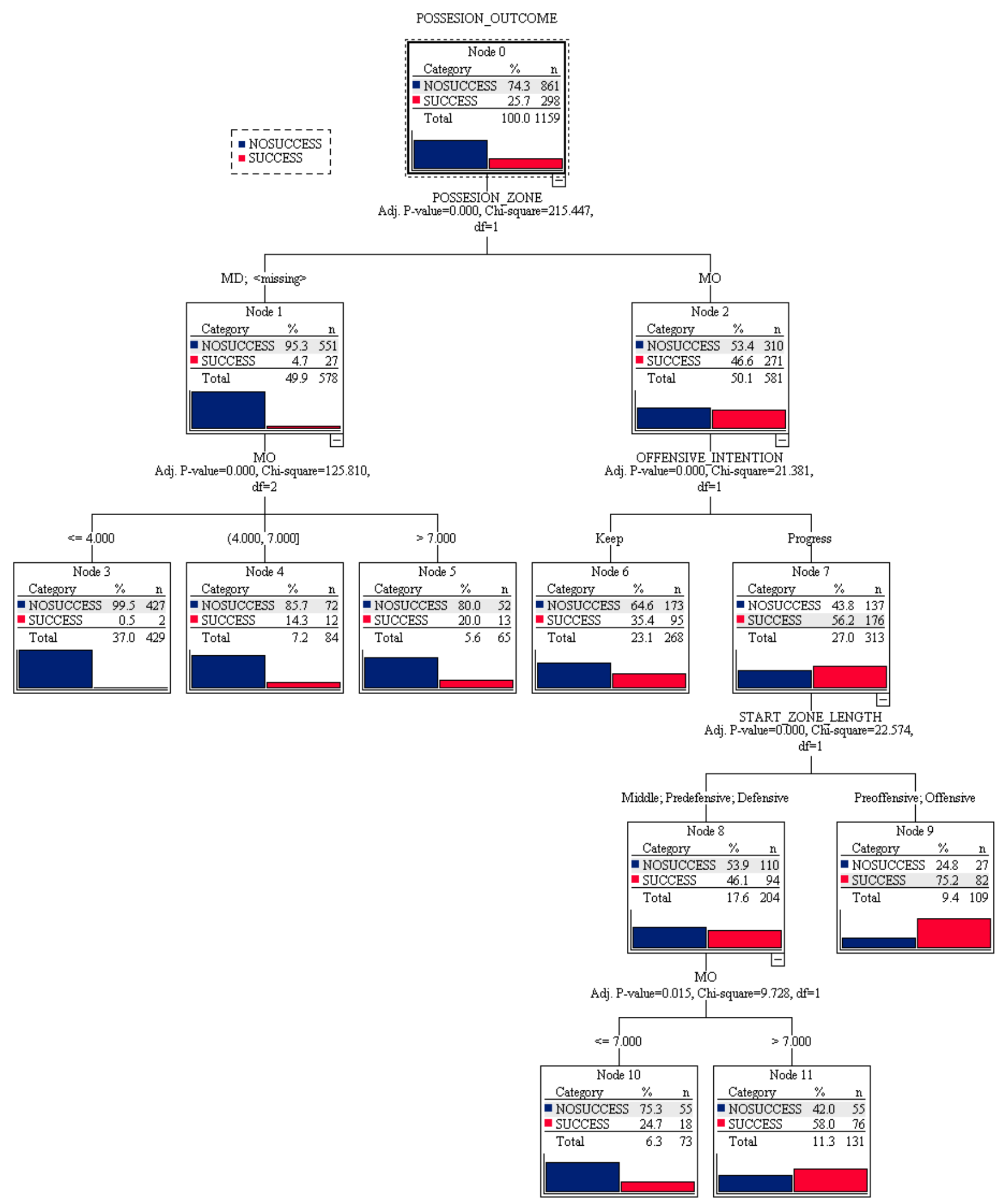

Figure 1. Predictive analysis of possessions outcome via decision tree. Note: $\mathrm{n}=$ frequency; $\mathrm{MD}=$ middle defensive; $\mathrm{MO}=$ middle offensive

On the other hand, nodes 6 and 7 of the decision tree input as predictive criteria the Offensive Intention $\left(\chi^{2}=21.381 ; p<0.001\right)$. Node 6 shows 269 observations and gives a possibility of success of $35.4 \%$ with the Keep category. However, when the Offensive Intention was progressed (node $7, \mathrm{n}=313$ ), the probability of obtaining Success in the 
offensive action was $56.2 \%$. Node 7 branches off into two, taking as predictive variable the Start Zone (length) $\left(\chi^{2}=22.574 ; p<0.001\right)$ in two nodes ( 8 and 9$)$, the second of which is terminal. Node 9, with the Pre-offensive and Offensive categories, shows a total of 109 observations classified as Success, $75.2 \%$ of them, with this node being that which shows the highest percentage of cases classified as Success. On the other hand, node 8 shows a total of 204 observations, classifying as Success $46.1 \%$ of cases when the Start Zone (length) was defensive, pre-defensive or middle.

The last criteria input by the algorithm from node 8 onwards was Possession Time in the Opponent's Half $(\mathrm{MO})\left(\chi^{2}=9.728 ; p<0.007\right)$. Two terminal nodes are produced for which are taken as a value of possession time in the opponent's half all those equal to or less than $7 \mathrm{~s}$ in node 10, obtaining probabilities of: $75.3 \%$ No Success and $24.7 \%$ Success out of a total of 73 observations. Lastly, node 11 obtains probabilities of $42 \%$ No Success and $58 \%$ Success for a total of 131 observations, taking all the values of possession time in the opponent's half $(\mathrm{MO})$ greater than $7 \mathrm{~s}$.

\subsection{Indirect Observation}

The tactical or contextual criteria that demonstrated a significant association with offensive success in women's football from polar coordinates analysis and sequential analysis of delays were: (i) physical, technical, tactical and cognitive aspects of players, (ii) offensive transitions, (iii) initial defensive intention, (iv) start form, (v) number of passes and attack duration and (vi) combinative attack and collective offensive technical aspects.

\section{Discussion}

The aims of this research were twofold: (i) to discover which are the contextual and tactical criteria that show association with success in elite women's soccer, and (ii) to establish a multivariate predictive model for the possessions from the analysed criteria. The sample used for the study was the FIFA Women's World Cup France 2019 [39]. In addition, eight semi-structured interviews with women's soccer coaches and players were transcribed ad verbatim and analysed by indirect observation.

A total of 2323 actions were analysed in 16 matches. This produced an average value of 145.2 actions per match, very close to the 147.66 actions observed by Jones et al. [12] in the English Premier League or the 135 observed by Barreira et al. [20] when they analysed the matches of the four semi-finalists in the FIFA World Cup 2010. Of the total of analysed actions, approximately $25 \%$ ended with relative success for the attacking team (Goal, Shot or Sent to Area) and just $1.1 \%$ ended in Goal.

Neither of the contextual criteria analysed-Match Status nor Match Outcomeshowed significant association with success in the possessions in this championship. The match status criteria are striking in that they proved to significantly influence ball possession in men's soccer $[12,14,25,26]$, modifying the possession zone and meaning that the teams had the ball closer to the rival goal when they were losing [14]. It was later observed that possession in offensive zones was favourable associated with the success of ball possessions Casal et al. [17]. On the other hand, Taylor et al. [15] showed that match status did not alter the technical behaviour of men's elite teams in domestic leagues, which is in line with the results obtained. In terms of the Time criteria, the results allow us to witness the existence of a greater probability of success during the last half hour of the match in comparison with the rest of the 15-min periods analysed. While these results may agree with those obtained by Sarmento et al. [26] this should be treated with caution. It is necessary to take into account the possible influence of the temporary result and the teams' need to score a goal when they are losing. These criteria can undoubtedly modify a teams' offensive behaviour when they are losing in the final minutes of the game, trying to send balls to the area quickly and ineffectively, thus modifying the statistical results obtained and leading us to draw erroneous conclusions.

The Start Zone (length) proved to be statistically significant by modifying the probability of obtaining success in offensive actions. Approximately one in every two actions 
analysed started off in the Defensive or Pre-defensive zone, corroborating previous studies that affirm a stable tendency in this sport towards ball possessions beginning in rear zones of the field of play $[19,20,22]$. On the other hand, the nearer to the rival goal is the start of the offensive action, the greater the probability of success in ball possessions. This was the very conclusion that Scanlan et al. [21] came to after analysing the creation of goal opportunities in the FIFA Women's World Cup Canada 2015. These results agree with the existing bibliography on men's elite soccer in which there is great consensus concerning the influence of these criteria on the success of possessions $[19,20,22,25,26]$. In relation to the above, we were able to note an important difference between the sexes in terms of soccer development that lies in the added difficulty in women's soccer of carrying out a pressurised release in the defensive zone through long passes. This technical deficiency could allow the opposing team to adopt advanced defensive positions that impede the release of the ball in technically inferior teams. In this sense, it is logical to think that those female soccer teams that are physically stronger would have technical-tactical advantages at this point of the game [3]. These results were argued by some of the interviewees:

Coach 1: "Long ball possessions allow other things, but goals always come from quick actions. [...] I believe that stealing the ball in opposite's half is the moment when the rival team will be disorganized and that is when you will have most probabilities of success"

Player 1: "I have lived it and I have seen it, the more advanced the recovery of the ball, the greater probability of success"

Coach 5: "The best strategy is the pressure after loss in opposite's half. For us, stealing the ball in the opponent's half as soon as possible is important because of the way we play"

It is therefore logical that the results obtained from analysing the Interaction Context would show the presence of more offensive interaction contexts in women's compared to men's elite soccer. In the sample analysed, around $10 \%$ of the actions began in a context with a high offensive value [24] AR or MR. These values are higher than those observed when analysing the men's EURO2008 and EURO2016 [19] in which the percentages were $3.77 \%$ and $8.74 \%$ respectively. These results appear logical for two reasons: firstly-as Kirkendall [2] states after interviewing different trainers of women's elite soccer-there might be lower technical quality in the specific post of defender in women's soccer; and secondly, the increased difficulty in covering long distances with the ball makes the players appear more lost on the ball in a sector of the field of play in which the opposing team shows more offensive interaction contexts. This justification was corroborated in the FIFA Women's World Cup France 2019 where it was observed that successful teams obtained a greater number of ball recoveries in the rival team's half [7]. In relation to this, the interviews considered that the technical-tactical aspects were a significant criterion in the proper development of ball possession in women's soccer:

Coach 1: "To unbalance a team that is defensively organized you have to be able to pass the ball effectively, decisively, to know when it is a short pass, when it should be a trough ball. If you don't do it right, it's impossible".

Coach 3: "Ball possession has two objectives: occupy more advanced areas and overcome rivals. The moment you advance, you are going to cause a player to have to advance and must become disorganized. During this process, the spaces you are going to occupy will appear, increasing the probabilities of success".

Player 3: "What makes the difference is the technical-tactical performance of the players. If you have players with greater passing efficacy, your ball possession will be safer. So, if you decide, your attack can be longer and will be more effective".

The second spatial criteria analysed-Start Zone (width)—did not present significant differences in terms of success. These results contradict those obtained by Scanlan et al. [18] who observed a higher probability of achieving goal opportunities in the women's world cup of 2015 when the start of the offensive phase was produced in the centre lane of the field of play.

Another criterion included in the observational instrument was Start Form. This criterion showed a significant influence on possession outcome $(p<0.05)$ in the same way 
that previous studies have demonstrated $[19,20]$. This factor appears to indicate that in women's soccer a dynamic start to the offensive action is a factor to be considered in the development of offensive actions, even more so taking into account the higher number of ball losses produced in women's soccer compared to men's [5,6]. This element seems logical if we consider that the team that recovers is in a position to exploit a certain space-time advantage due to the defensive disorganisation of the rival team [20]. In relation to all of the above, the Defensive Organization of the rival team was also a significant variable $(p<0.001)$ : when the opposing team was defensively disorganised at the point of the start of the offensive action, the probabilities of success rose threefold.

The Defensive Positioning and Defensive Intention criteria presented significant differences with success $(p<0.001)$. The two criteria may be related-while it would be necessary to carry out different investigations into these aspects-with Start Zone (Length) and Defensive Organization. In this sense, it would appear logical to think that when teams recover the ball in zones near to the rival goal, the defending team is positioned in its own half and therefore presents deeper defensive positioning. Similarly, when a team loses possession of the ball and is not defensively organised there will be a collective defensive intention directed at carrying out a rapid defence of their own goal by trying to slow down the attacking team's advance. In relation to Vogelbein et al. [27] observations in the Bundesliga, which demonstrated that the best teams recovered the ball more quickly and via more pressurised intentions, the results of this study could suggest a similar tendency in women's elite soccer, even though the limitations of the study concerning this variable do not allow us to form clear conclusions.

Player 4: "The best teams are teams that dominate their matches. For example, France and the USA are teams that do "gegenpressing" for their great physical performance and because they have more possession than their rivals".

Another of the analysed criteria that showed significant statistical differences with success was the Offensive Intention $(p<0.001)$. According to the results obtained, we can affirm that there was approximately twice the probability of success when the team attempted to Progress rapidly towards the rival goal, compared with possessions in which it tried to keep possession of the ball. The results obtained by Maneiro et al. [22] in men's elite soccer are also along these lines.

Finally, the results obtained from analysing the influence of the continuous criteria on the success of offensive actions were interpreted. Of the four criteria included in the ad hoc observation instrument, three of them showed significant differences depending on the result of the possession: Possession Time in Own Half (MD) $(p<0.001)$, Possession Time in Opponent's Half $(\mathrm{MO})(p<0.001)$ and Passes $(p<0.005)$, although the total possession time did not influence the result of the possessions $(p=0.265)$. Scanlan et al. [18] obtained similar results in the FIFA Women's World Cup 2015; in this championship, there were no significant differences observed in the duration of the offensive actions that ended in a goal compared with those that ended unsuccessfully. In terms of number of passes, despite there being significant differences, it is thought necessary to enlarge the study of this variable in women's soccer according to the results obtained, with a view to seeing whether its influence on offensive success is similar to that observed in other studies among men [24,25].

In relation to the previous criteria, we can affirm that the Possession Zone $(p<0.001)$ was a variable that modified the success of the possessions in the Women's World Cup France 2019. In agreement with Casal et al. [17] the results obtained appear to suggest that the development of possession of the ball in the opponent's half is an indicator of success in the possessions in women's soccer, although we should be cautious when extracting general conclusions about women's soccer due to the specific nature of the sample analysed. A possible justification for this may be the greater technical-tactical performance of the players of the best teams when developing attacks in areas with higher player density: 
Coach 4: "The longer you have the ball in the opponent's half, the greater the probability of success you will have. I think that ball possession in own's half does not contribute anything to the offensive process".

Player 3: "I think that talented players make it possible to win matches because they don't need space and time: [ ... ] Their decision-making is faster than other players and their technical performance allows them not to need space to generate scoring opportunities".

Coach 1: "Soccer is about perception and constant decision making. [ ... ] Taking that into account, our players must be thinking before receiving the ball. This is how we manage to speed up the offensive process".

Finally, analysis of the decision tree carried out in this study allows us to corroborate the influence of the aforementioned criteria. From the criteria introduced by the tree's algorithm, we can see that the Possession Zone was the criteria that most influenced the process of possessions in this edition of the FIFA Women's World Cup France 2019. When possession of the ball was developed largely in MD, the probability of success was barely $5 \%$, against the $46.6 \%$ observed when the possession zone was MO. Following the straight branches of the decision tree, the algorithm introduced the Offensive Intention criteria which increased the probability of success in possession to $56.2 \%$ when the initial intention was Progress. The highest probability of Success $(75.2 \%)$ was observed when the Start Zone (Length) was Pre-offensive or Offensive. In this sense, we can see a clear similitude with different studies of men's soccer in observing that the criteria that show association with success in possessions are the Possession Zone [14,17], Offensive Intention [22,25,26] and the Start Zone (Length) $[19,20,22]$.

\section{Conclusions}

According to the results obtained in the current research, it can be concluded that the greatest probability of finishing ball possession successfully in women's soccer occurs when: (i) most of the possession time takes place in the opponent's half, (ii) there is an initial offensive intention to progress quickly towards the rival goal once possession of the ball has been recovered and (iii) the start zone of the possession is pre-offensive or offensive. In addition, based on the analysis carried out on the transcripts of the interviews with coaches and players, criteria related to technical-tactical performance, decision-making and physical capacities of the players will be decisive in increasing the probabilities of success. Based on the results obtained in both analyzes, it is possible to conclude the need to start ball possessions in areas close to the rival goal and to develop an intention to progress quickly. In this situation, in which the center of the game will be in a high density of players area, offensive success will be conditioned to the technical-tactical performance of the attacking players, the speed and efficiency in their decision making, and their physical abilities to take advantage of the situation of defensive disorder that transition moments represents in elite soccer.

Whilst these results could be useful for trainers and players in training and competition, we consider it necessary to further develop knowledge of ball possessions in women's elite soccer in future research.

\section{Limitations and Future Lines of Research}

The results obtained in this study suppose an approach to the behaviors to be developed in the achievement of offensive success in elite women's soccer. Despite this, one of the limitations of this study is the fact that the analysis of a single championship does not allow to draw conclusions about the complex reality of the offensive phase in women's soccer. Likewise, it is necessary to carry out more studies in which coaches and players participating in the tournaments analyzed allow obtaining significant results about the criteria that determine offensive success. Under this premise, mixed methods are postulated as an optimal paradigm in carrying out future related research. 
Author Contributions: Conceptualization, I.I.-B. and A.A. methodology I.I.-B., R.M. and J.L.L. formal analysis, I.I.-B. and J.L.L. reviewers, R.M., J.L.L. and A.A. writing-original draft preparation, I.I.-B. writing-review and editing, R.M., J.L.L. and A.A. visualization, I.I.-B. supervision, R.M., J.L.L. and A.A. All authors have read and agreed to the published version of the manuscript.

Funding: This research received no external funding.

Institutional Review Board Statement: This study was approved by the Research and Teaching Ethics Committee of the Universidade da Coruña (approval number: CEID-UDC-2019-0024).

Informed Consent Statement: Informed consent was obtained from all subjects involved in the study.

Data Availability Statement: Not applicable.

Acknowledgments: The authors gratefully acknowledge the support of a Spanish government subproject Mixed method approach on performance analysis (in training and competition) in elite and academy sport [PGC2018-098742-B-C33] (2019-2021) [del Ministerio de Ciencia, Innovación y Universidades (MCIU), la Agencia Estatal de Investigación (AEI) y el Fondo Europeo de Desarrollo Regional (FEDER)], that is part of the coordinated project New approach of research in physical activity and sport from mixed methods perspective (NARPAS_MM) [SPGC201800X098742CV0]. Also, the authors thank the coaches and players participating in the research.

Conflicts of Interest: The authors declare no conflict of interest.

\section{References}

1. Lord, F.; Pyne, D.B.; Welvaert, M.; Mara, J.K. Methods of performance analysis in team invasions sport: A systematic review. J. Sport. Sci. 2020, 38, 2338-2349. [CrossRef]

2. Kirkendall, D.T. Issues in training the female player. Br. J. Sports. Med. 2007, 41, 64-67. [CrossRef]

3. De Jong, L.M.S.; Gastin, P.B.; Angelova, M.; Bruce, L.; Dwyer, D.B. Technical determinants of success in professional women's soccer: A wider range of variables reveals new insights. PLOS ONE 2020, 15. [CrossRef]

4. Hewitt, A.; Norton, K.; Lyons, K. Movement profiles of elite women soccer players during international matches and the effect of opposition's team ranking. J. Sport. Sci. 2014, 32, 1874-1880. [CrossRef]

5. Bradley, P.S.; Dellal, A.; Mohr, M.; Castellano, J.; Wilkie, A. Gender differences in match performance of soccer players competing in the UEFA Champions League. Hum. Mov. Sci. 2013, 33, 159-171. [CrossRef] [PubMed]

6. Casal, C.A.; Losada, J.L.; Maneiro, R.; Ardá, A. Gender differences in technical-tactical behaviour of La Liga Spanish football teams. J. Hum. Sport. Exercise 2020, 16, 37-52. [CrossRef]

7. Kubayi, A.; Larkin, P. Technical performance of soccer teams according to match outcome at the 2019 FIFA Women's World Cup. Int. J. Perf. Anal. Sport. 2020, 20, 908-916. [CrossRef]

8. Sarmento, H.; Clemente, F.M.; Gonçalves, E.; Harper, L.D.; Dias, D.; Figueiredo, A. Analysis of the offensive process of AS Monaco professional soccer team: A mixed-method approach. Chaos Solitions Fractals 2020, 133. [CrossRef]

9. Sarmento, H.; Anguera, M.T.; Pereira, A.; Marques, A.; Campaniço, J.; Leitao, J. Patterns of Play in the Counterattack of Elite Football Teams-A Mixed Method Approach. Int. J. Perf. Anal. Sport. 2014, 14, 411-427. [CrossRef]

10. Casal, C.A.; Anguera, M.T.; Maneiro, R.; Losada, J.L. Possession in Football: More than a Quantitative Aspect-A Mixed Method Study. Front. Psychol. 2019, 10, 501. [CrossRef]

11. Hughes, M.D.; Barlett, R.M. The use of performance indicators in performance analysis. J. Sport. Sci. 2002, 20, 739-754. [CrossRef]

12. Jones, P.D.; James, N.; Mellalieu, S.D. Possession as a performance indicator in soccer. Int. J. Perf. Anal. Sport. 2004, 4, 98-102. [CrossRef]

13. Kite, C.S.; Nevill, A. The Predictors and Determinants of Inter-Seasonal Success in a Professional Soccer Team. J. Hum. Kin. 2017, 58, 157-167. [CrossRef] [PubMed]

14. Lago, C. The influence of match location, quality of opposition, and match status on possession strategies in professional association football. J. Sport. Sci. 2009, 27, 1463-1469. [CrossRef] [PubMed]

15. Taylor, J.B.; Mellalieu, S.D.; James, J.; Shearer, D.A. The influence of match location, quality of opposition, and match status on technical performance in professional association football. J. Sport. Sci. 2008, 26, 885-895. [CrossRef]

16. James, N.; Mellalieu, S.D.; Hollely, C. Analysis of strategies in soccer as a function of European and domestic competition. Int. J. Perf. Anal. Sport. 2002, 2, 85-103. [CrossRef]

17. Casal, C.A.; Maneiro, R.; Ardá, T.; Marí, F.J.; Losada, J.L. Possession Zone as a Performance Indicator in Football. The Game of the Best Teams. Front. Psychol. 2017, 8, 1176. [CrossRef]

18. Maneiro, R.; Losada, J.L.; Casal, C.A.; Ardá, A. The influence of match status on ball possession in high performance women's football. Front. Psychol. 2020, 11, 487. [CrossRef]

19. Almeida, C.H.; Ferreira, A.P.; Volossovitch, A. Effects of Match Location, Match Status and Quality of Opposition on Regaining Possession in UEFA Champions League. J. Hum. Kin. 2014, 41, 203-214. [CrossRef] 
20. Barreira, D.; Garganta, J.; Guimaraes, P.; Machado, J.; Anguera, M.T. Ball recovery patterns as a performance indicator in elite soccer. J. Sport. Eng. Technol. 2014, 228, 61-72. [CrossRef]

21. Scanlan, M.; Harms, C.; Cochrane Wilkie, J.; Ma'yah, F. The creation of goal scoring opportunities at the 2015 women's world cup. Int. J. Sports. Sci. Coach. 2020, 15, 803-808. [CrossRef]

22. Maneiro, R.; Casal, C.A.; Álvarez, I.; Moral, J.E.; López, S.; Ardá, A.; Losada, J.L. Offensive Transitions in High-Performance Football: Differences Between UEFA Euro 2008 and UEFA Euro 2016. Front. Psychol. 2019, 10. [CrossRef]

23. Castellano, J. Observación y Análisis de la Acción de Juego en el Fútbol [Observation and Analysis of Game Action in Football]. Ph.D. Thesis, University of País Vasco, Vitoria-Gasteiz, Spain, 2000.

24. Castellano, J.; Hernández-Mendo, A. Polar coordinate analysis for estimating relationships in motor interaction in football. Psichotema 2003, 15, 569-574.

25. Lago-Ballesteros, J.; Lago-Peñas, C.; Rey, E. The effect of playing tactics and situational variables on achieving score-box possessions in a professional soccer team. J. Sport. Sci. 2012, 30, 1455-1461. [CrossRef] [PubMed]

26. Sarmento, H.; Figueiredo, A.; Lago-Peñas, C.; Milanovic, Z.; Barbosa, A.; Tadeu, P.; Bradley, P.S. Influence of Tactical and Situational Variables on Offensive Sequences During Elite Football Matches. J. Strength. Cond. Res. 2018, 32, 2331-2339. [CrossRef] [PubMed]

27. Vögelbein, M.; Nopp, S.; Hökelmann, A. Defensive transition in soccer-Are prompt possession regains a measure of success? A quantitative analysis of German Fußball-Bundesliga 2010/2011. J. Sport. Sci. 2014, 32, 1076-1083. [CrossRef] [PubMed]

28. Aranda, R.; González-Rodenas, J.; López-Bondía, I.; Aranda-Malavés, R.; Tudela-Desantes, A.; Anguera, M.T. “REOFUT” as an Observational Tool for Tactical Analysis on Offensive Performance in Soccer: Mixed Method Perspective. Front. Psychol. 2019, 10, 1476. [CrossRef]

29. Santos, P.; Lago-Peñas, C.; García-García, O. The influence of situational variables on defensive positioning in professional soccer. Int. J. Perf. Anal. Sport 2017, 3, 212-219. [CrossRef]

30. Tenga, A.; Kanstad, D.; Ronglan, L.T.; Bahr, R. Developing a New Method for Team Match Performance Analysis in Professional Soccer and Testing its Reliability. Int. J. Perf. Anal. Sport 2009, 9, 8-25. [CrossRef]

31. Okohlm Kryger, K.; Wang, A.; Mehta, R.; Impellizeri, F.M.; Massey, A.; McCall, A. Research on women's football: A scoping review. Sci. Med. Football 2021. [CrossRef]

32. Maneiro, R.; Casal, C.A.; Ardá, A.; Losada, J.L. Application of multivariant decision tree technique in high performance football: The female and male corner kick. PLoS ONE 2019, 14, e0212549. [CrossRef]

33. FIFA. Women's Football. Member Associations Survey Report. 2019. Available online: https://img.fifa.com/image/upload/nq3 ensohyxpuxovcovj0.pdf (accessed on 21 April 2021).

34. Johnson, R.B.; Onwuegbuzie, A.J.; Turner, L.A. Toward a definition of mixed methods research. J. Mix. Methods Res. 2007, 1, 112-133. [CrossRef]

35. Anguera, M.T.; Portell, M.; Chacón-Moscoso, S.; Sanduvete-Chaves, S. Indirect Observation in Everyday Contexts: Concepts and Methodological Guidelines within a Mixed Method Framework. Front. Psychol. 2018, 30, 13. [CrossRef]

36. Anguera, M.T. Observational Typology. Qual. Quan. 1979, 13, 449-484. [CrossRef]

37. Anguera, M.T.; Blanco-Villaseñor, A.; Hernández-Mendo, A. Diseños observacionales: Ajuste y aplicación en psicología del deporte [Observational designs: Their suitability and application in sports Psychology]. Cuad. Psicol. Dep. 2011, 11, 63-76.

38. FIFA. FIFA Women's World Cup France 2019. Global Broadcast and Audience Report. 2019. Available online: https: / / resources.fifa.com/image/upload/fifa-women-s-world-cup-france-2019tm-global-broadcast-and-audience-report. pdf?cloudid=u7uerxw2bejdlsi8fswn (accessed on 21 April 2021).

39. FIFA. Technical Report: FIFA Women's World Cup France 2019. Available online: https:/ / resources.fifa.com/image/upload/fifatechnical-study-group-fifa-women-s-world-cup-france-2019tm-technical-report.pdf?cloudid=lnpeuvaoc1v5tih9rf7p (accessed on 21 April 2021).

40. Garganta, J. Modelaçao Táctica do Jogo de Futebol. Estudo da Organizaçao da Fase Ofensiva em Equipas de Alto Rendimiento. Ph.D. Thesis, Universidade do Porto, Porto, Portugal, June 1997.

41. Anguera, M.T. Metodología selectiva en psicología del deporte [Selective methodology in sport Psychology]. In Psicología del Deporte (Vol. II). Metodología; Hernández-Mendo, A., Ed.; Wanceulen Editorial S.L.: Sevilla, Spain, 2005; pp. $67-98$.

42. Anguera, M.T. Desarrollando la observación indirecta: Alcance, proceso y habilidades metodológicas en el análisis de textos [Development of indirect observation: Scope, process and methodological abilities in textual analysis]. In Patrones de Habilidades Metodológicas y Conceptuales de Análisis, Evaluación e Intervención en Ciencias del Comportamiento; Santoyo, C., Ed.; UNAM/PAPPIIT: Ciudad de México, Mexico, 2019; in press.

43. Casal, C.A.; Andújar, M.A.; Losada, J.L.; Ardá, T.; Maneiro, R. Identification of Defensive Performance Factors in the 2010 World Cup South Africa. Sports 2016, 4, 54. [CrossRef] [PubMed]

44. Duarte, R.; Araujo, D.; Correia, V.; Davids, K. Sports Teams as Superorganisms. Implications of Sociobiological Models of Behaviour for Research and Practice in Team Sports Performancer Analysis. Sport Med. 2012, 42, 633-642. [CrossRef]

45. Izquierdo, C.; Anguera, M.T. The Analysis of Interpersonal Communication in Sport From Mixed Methods Strategy:"The Integration of Qualitative-Quantitative Elements Using Systematic Observation. Front. Psychol. 2021, 12. [CrossRef] [PubMed]

46. Soto, A.; Camerino, O.; Iglesias, X.; Anguera, M.T.; Castañer, M. LINCE PLUS: Research Software for Behaviour Video Analysis. Apunts. Educ. Fís. Deporte. 2019, 137, 149-153. [CrossRef] 
47. Losada, J.L.; Manolov, R. The process of basic training, applied training, maintaining the performance of an observer. Qual. Quant. 2015, 49, 339-347. [CrossRef]

48. Cohen, J. A coefficient of agreement for nominal scales. Ed. Psychol. Meas. 1960, 20, 37-46. [CrossRef]

49. Landis, J.R.; Koch, G.G. The measurement of Observer Agreement for Categorical Data. Biometrics 1977, 33, 159-174. [CrossRef]

50. Giménez, J.V.; Jiménez-Linares, L.; Leicht, S.A.; Gómez, M.A. Predictive modelling of the physical demands during training and competition in professional soccer players. J. Sci. Med. Sport. 2020, 23, 603-608. [CrossRef]

51. Casal, C.A.; Losada, J.L.; Maneiro, R.; Ardá, T. Influencia táctica del resultado parcial en los saques de esquina en fútbol [Influence of match status on cormer kick in elite soccer. Rev. Int. Med. Cienc. Act. Fís. Deporte 2017, 17, 715-728. [CrossRef]

52. Méndez-Domínguez, C.; Gómez-Ruano, M.A.; Ruiz-Pérez, L.M.; Travassos, B. Goals scored and received in 5vs4 GK game strategy are constrained by critical moment and situational variables in elite futsal. J. Sport. Sci. 2019, 37, 2443-2451. [CrossRef]

53. Robertson, S.; Back, N.; Bartlett, J.D. Explaining match outcome in elite Australian Rules football using team performance indicators. J. Sport. Sci. 2016, 34, 637-644. [CrossRef] [PubMed]

54. Hernández-Mendo, A.; López-López, J.A.; Castellano, J.; Morales-Sánchez, V.; Pastrana, J.L. Hoisan 1.2: Programa informático para uso en metodología observacional [Hoisan 1.2: Software for Observational methodology]. Cuad. Psicol. Deporte 2012, 12, 55-78. [CrossRef] 